\title{
Fundus flavimaculatus
}

\author{
C. P. GUPTA
}

Madras, India

\section{Case report}

A youth aged 17 years, first seen in June, I97I, had had defective vision since childhood and increased difficulty in reading small print for the past 3 years. There was no difference between night and day vision, and no history of similar trouble in his family.

\section{Examination}

The visual acuity was $6 / 60, \mathrm{~N}_{4}$ in the right eye and $5 / 60, \mathrm{~N}_{4}$ in the left. The pupils were equal and reacted to light and convergence. The media were clear, and the optic discs and vessels normal. Both fundi showed yellowish-white patches deep to the retinal vessels, of various shapes and sizes (Fig. I). The yellowish-white patches in the central area were small and round and had the appearance of colloid bodies. Some had the typical 'fishtail' or 'pisciform' appearance described in this condition. Both maculae showed pigmentary mottling with a greyish sheen (Fig. 2). Complete colour blindness was shown by testing with Ishihara colour plates. Perimetry with $3 / 330$ white object showed concentric contraction to $50^{\circ}$ in the right eye and $40^{\circ}$ in the left.

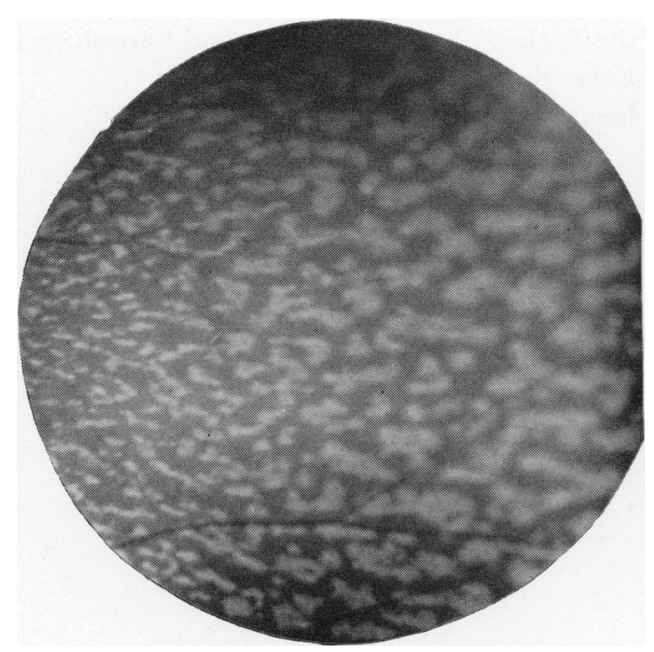

FIG. I Equatorial region of right fundus, showing typical 'pisciform' or 'fishtail' yellowish-white patches

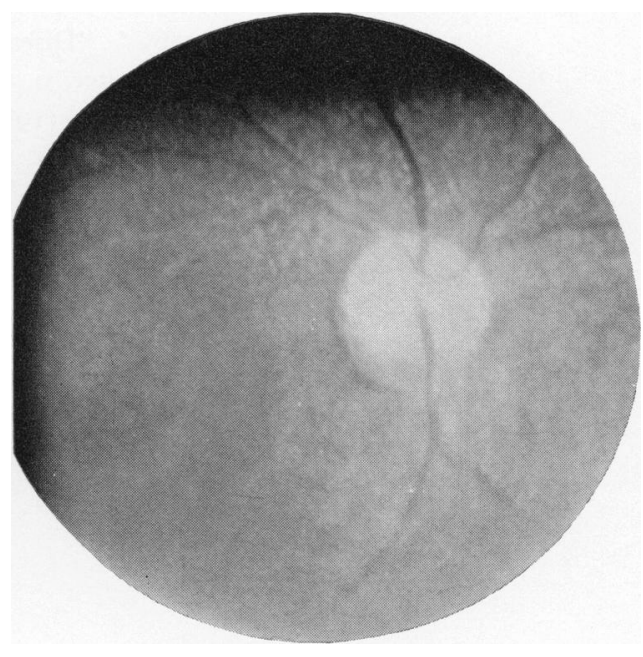

FIG. 2 Optic disc and macula of left fundus, showing pigmentary mottling of the macula

The father and two sisters were examined and found to be normal; the mother was reported to be aphakic but otherwise normal.

\section{Discussion}

The term 'fundus flavimaculatus' was introduced by Franceschetti (1962). The subject was reviewed by Klien and Krill ( 1967 ) with a report of 27 cases and one histological 
examination. They showed that there was a definite histological pattern of mucopolysaccharide deposits in the inner layers of the pigment epithelium, distinguishing them from colloid bodies. Fluorescence retinal photography showed widespread background mottling (Brown and Hill, I968). The genetic pattern is not definitely known although both dominant and recessive patterns have been described (Duke-Elder and Dobree, 1967).

This condition is often misdiagnosed as tapeto-retinal dystrophy, but can be distinguished by the typical morphological appearance, benign course, normal or near normal dark adaptation, and minimal field loss. The electroretinogram and electro-oculogram may be normal or slightly reduced. Though familial cases have been described, no history of similar lesions in other members of the family has been obtained in many cases.

\section{Summary}

A case of fundus flavimaculatus is described, and the differential diagnosis from tapeto-retinal dystrophy discussed.

I am grateful to the Superintendent, Government Ophthalmic Hospital, Madras, for permitting me to report this case, and to Dr. J. Agrawal for the fundus photographs.

\section{References}

BRoWN, N., and HILL, D. W. (1968) Brit. F. Ophthal., 52, 849

DUKE-ELDER, S., and DOBREE, J. H. (1967) "System of Ophthalmology", vol. 1o, p. 628. Kimpton, London

FRANCESCHETTI, A. (1962) "Diseases of the Retina", in "Entwicklung und Fortschritt in der Augenheilkunde", ed. H. Sautter, p. 107. Enke, Stuttgart

KLIEN, B. A., and Krill, A. E. (I967) Amer. F. Ophthal., 64, 3

\section{Correction}

In the article by H. B. Chawla and C. H. Birchall in the January issue (Brit. F. Ophthal., 1973, 57, 60), on p. $61,1.24$, for contract read contact.

To gauge the required tension, the band should be tightened to conTact the globe deep to the rectus insertions. 